\title{
Locally Advanced Bile Duct Carcinoma
}

National Cancer Institute

\section{Source}

National Cancer Institute. Locally Advanced Bile Duct Carcinoma. NCI Thesaurus. Code C151971.

A bile duct carcinoma that has spread to nearby tissues or lymph nodes. 